\section{ORIGINAL RESEARCH}

\author{
J. Hammersley \\ V. Haughton \\ Y. Wang
}

A. Munoz del Rio

\title{
Tapering of the Cervical Spinal Canal in Patients with Scoliosis with and without the Chiari I Malformation
}

\begin{abstract}
BACKGROUND: Cervical spinal canal tapering may increase CSF velocities and pressures. One report suggests that the cervical spinal canal tapers more steeply in patients with Chiari I than in healthy subjects. The goal of this study was to test the conclusion by measuring spinal canal tapering in another cohort of patients.
\end{abstract}

\begin{abstract}
MATERIALS AND METHODS: Consecutive patients with scoliosis and MR imaging were selected. The MR images were evaluated for tonsillar herniation and syringomyelia. On a midline T2-weighted MR image, the anteroposterior diameter of the spinal canal was measured at each cervical level, and a linear trend line was fit by least-squares regression. The slope of this line was recorded as the taper ratio in millimeters/level. Patients with $>5 \mathrm{~mm}$ of tonsillar herniation (with or without syrinx) were compared with those without tonsillar herniation (with or without syrinx). Differences in taper ratios for the 2 groups were tested for significance by the Kruskal-Willis test with significance set at .05 .

RESULTS: Fifty-four patients with scoliosis were identified; 22 had a Chiari malformation and 32 did not. Syringomyelia was identified in 20 of the patients with Chiari and in 8 of the others. The taper ratios averaged $-0.9 \mathrm{~mm} / \mathrm{level}$ for the patients with a Chiari malformation (with or without a syrinx) and $-0.4 \mathrm{~mm} / \mathrm{level}$ for those without it, significant at $P=.035$. Syringomyelia did not substantially alter the taper ratio in either group.
\end{abstract}

CONCLUSIONS: Patients with scoliosis with a Chiari malformation have more steeply tapering cervical spinal canals than those without it.

$T^{T}$ he small posterior fossa in Chiari malformation has suggested a mesodermal abnormality, which may be the cause of the low position of the tonsils. The possibility that a mesodermal disorder involves the cervical spine has not been adequately studied, to our knowledge. We hypothesized that the cervical spinal canal tapers more severely in patients with the Chiari malformation than in patients without it. One study supported this hypothesis. ${ }^{1}$ Because a large cohort of patients was not included in the first report, we attempted to test the hypothesis in a larger cohort of patients.

Patients with scoliosis seemed a suitable population for the test. Patients undergoing evaluation for scoliosis have a relatively narrow age range, an advantage for the study because spinal canal tapering varies significantly with age. ${ }^{1}$ Up to onethird of patients with scoliosis have syringomyelia, Chiari malformation, or a combination of the $2{ }^{2}$ with the combination occurring most commonly. ${ }^{3}$ Furthermore, scoliosis is considered one of the many sequelae of a Chiari malformation, and if found in a patient with Chiari I, it may be an indication for craniovertebral decompression, the most common surgical treatment for Chiari I. The possibility of a Chiari malformation or syringomyelia in patients with scoliosis motivates the acquisition of MR imaging in some cases. Scoliosis also occurs without syringomyelia or Chiari I malformation. We designed

Received October 27, 2011; accepted after revision December 23.

From the Departments of Radiology (J.H., V.H., Y.W., A.M.d.R.) and Radiology and Medical Physics (A.M.d.R.), University of Wisconsin School of Medicine and Public Health, Madison, Wisconsin

Please address correspondence to V. Haughton, MD, Department of Radiology, University of Wisconsin School of Medicine and Public Health, 600 Highland Ave, Madison, WI 53792; e-mail: vmhaughton@wisc.edu

http://dx.doi.org/10.3174/ajnr.A3046 a study to compare the degree of spinal canal tapering in patients with scoliosis with and without a Chiari I malformation.

\section{Materials and Methods}

The institutional review board at the University of Wisconsin School of Medicine and Public Health approved this retrospective study and waived the requirement for written informed consent. This study conformed to Health Insurance Portability and Accountability Act standards.

We searched the PACS of our institution for patients with the keyword scoliosis between 2004 and 2010. We selected for inclusion all patients identified in the search who had a "scoliosis series" of spine radiographs and either a total spine MR imaging or a cervical and thoracic spine MR imaging. Patients who had a history of back surgery or spinal trauma, spine anomalies such as hemivertebrae or diastematomyelia, muscular dystrophies or bone dysplasias, or spinal tumors or infections were excluded.

Spine radiographs were evaluated for the degree of scoliosis. Inclusion criteria were a Cobb angle $\geq 15^{\circ}$. MR images in each case were reviewed for evidence of tonsillar herniation and/or syrinx. Tonsillar herniation was measured by placing a line from the tip of the clivus to the opisthion and measuring from this line to the tip of the cerebellar tonsils, by using software in the PACS. Patients with $>5 \mathrm{~mm}$ of tonsillar herniation were classified as having Chiari I. Patients with tonsillar herniation between 1 and $5 \mathrm{~mm}$ were excluded. The diagnosis of syrinx was applied to a well-defined homogeneous process within the spinal cord with the signal intensity of CSF in both T1- and T2weighted images. The location and craniocaudal extent of any syrinx were recorded. The location (cervical or thoracic) and the type (levoor dextroscoliosis or both) were noted. The Cobb angle and scoliosis metrics were tabulated. Patients were classified on the basis of tonsil location as having scoliosis with Chiari malformation or without Chiari malformation. 


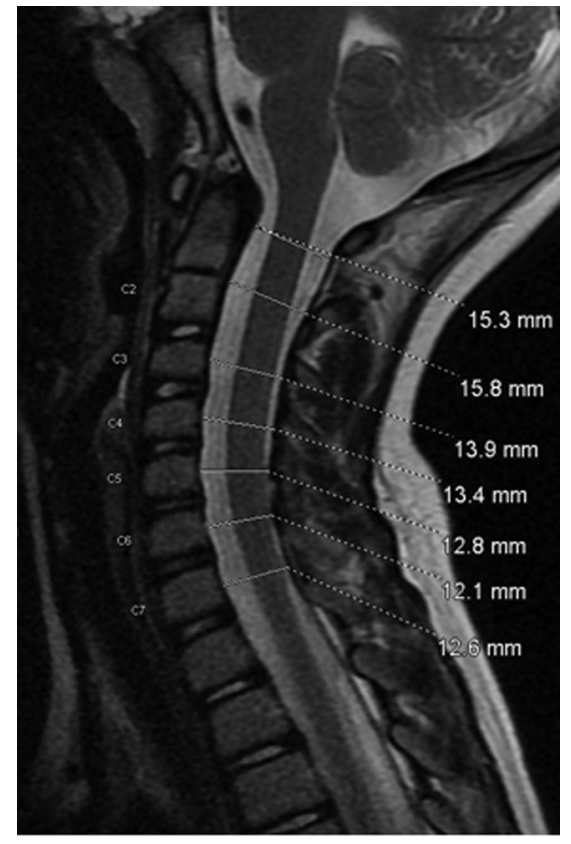

Fig 1. Sagittal T2-weighted MR image showing measurements of the anteroposterior diameter for $\mathrm{C} 1$ through $\mathrm{C} 7$.

The T2-weighted sagittal cervical spine series was reviewed, windowed, and leveled until the C1-C7 subarachnoid space was optimally displayed. The image or images displaying the midline central canal, as determined from the appearance of the dens in the upper spine or the appearance of the spinous processes in the lower spine, were selected. With software resident in the scanner console, the anteroposterior diameter of the spinal canal was measured for each cervical level at the midportion of the vertebral body, along a line perpendicular to the spinal axis extending from the anterior to the posterior edge of the subarachnoid space (Fig 1). Multiple images were examined in patients with cervical scoliosis to assess midline diameters at all cervical levels. For C1, the midportion of the anterior arch was used.

The spinal canal diameters were plotted against the cervical spine level for each patient. An algorithm resident in the Excel (Microsoft, Bothell, Washington) spreadsheet calculated a linear trend line to the scatterplots by least-squares regression (Fig 2). The slope of this line in millimeters/level was recorded as the taper ratio for the patient, with a negative sign indicating a taper toward C7. Differences between patients with and patients without a Chiari malformation were tested for significance by the Kruskal-Wallis test with significance set at .05 . Significance was also tested in the subgroups of patients with a syrinx. The taper ratios were calculated similarly for C1-C4 by plotting the diameters and calculating the trend lines.

Interobserver variability was measured in a subset of 18 patients. Three readers ( 1 neuroradiologist, 1 first-year radiology resident, and 1 undergraduate student trained in measuring the anteroposterior diameter of the spinal canal) measured the diameters in the same groups of patients. The 3 readers were blinded to the results of the other readers. Reader bias and limits of agreement were calculated. ${ }^{4}$

\section{Results}

The search of the PACS identified 56 patients with scoliosis who met the criteria for inclusion. Two with tonsillar herniation between 1 and $4 \mathrm{~mm}$ were excluded. Of the remaining 54

\section{Spinal Canal Diameter}

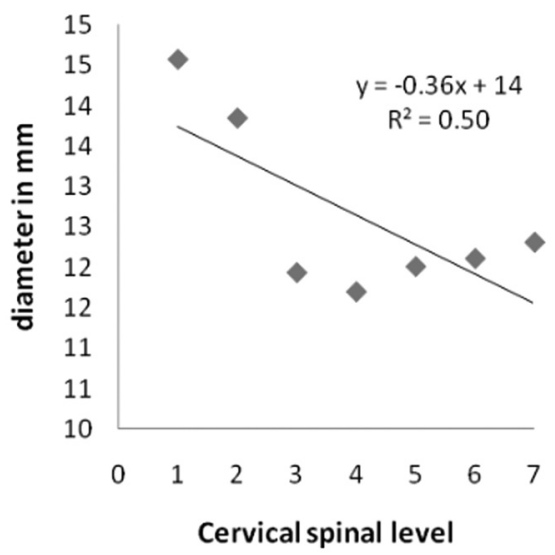

Fig 2. Trend line fit by least squares to the diameters of the spinal canal. The slope is -0.36 , and the quality of fit $\left(R^{2}\right)$ is 0.5 .

\begin{tabular}{|c|c|c|c|c|c|c|}
\hline \multicolumn{7}{|c|}{$\begin{array}{l}\text { Number, sex, tonsillar location, and Cobb angles of patients } \\
\text { analyzed }\end{array}$} \\
\hline & No. & Females & $\begin{array}{c}\text { Mean } \\
\text { Age } \\
\text { (yr) }\end{array}$ & $\begin{array}{c}\text { Age } \\
\text { Range } \\
\text { (yr) }\end{array}$ & $\begin{array}{l}\text { Minimum } \\
\text { Tonsillar } \\
\text { Herniation } \\
\text { (mm) }\end{array}$ & $\begin{array}{c}\text { Mean and } \\
\text { Range of } \\
\text { Cobb Angles }\end{array}$ \\
\hline Chiari & 2 & 1 & 9 & $3-14$ & 25 & $18^{\circ}\left(16^{\circ}-19^{\circ}\right)$ \\
\hline $\begin{array}{l}\text { Chiari plus } \\
\text { syrinx }\end{array}$ & 20 & 11 & 9 & $12-19$ & 8 & $34^{\circ}\left(15^{\circ}-87^{\circ}\right)$ \\
\hline Syrinx only & 8 & 3 & 10 & $1-17$ & $\mathrm{~N} / \mathrm{A}$ & $20^{\circ}\left(15^{\circ}-40^{\circ}\right)$ \\
\hline $\begin{array}{l}\text { No Chiari or } \\
\text { syrinx }\end{array}$ & 24 & 19 & 11 & $1-18$ & $\mathrm{~N} / \mathrm{A}$ & $35^{\circ}\left(15^{\circ}-82^{\circ}\right)$ \\
\hline
\end{tabular}

Note:-N/A indicates not applicable.

patients, 22 were classified as having Chiari I, including 20 who had a syrinx, and 32 patients were classified in the nonChiari group, including 8 with a syrinx. The 54 patients included 34 females and 20 males. The mean patient age was 10 years, with an age range of $1-19$ years. The age and sex for each of the groups are shown in the Table. The tonsil measurements exceeded $8 \mathrm{~mm}$ in all patients with Chiari. The Cobb angle and patterns of syrinx location and of scoliosis characteristics did not appear to differ between groups with and without the Chiari malformation. For example, in patients with both Chiari and syrinx, the mean Cobb angle was $34^{\circ}$, and in the group with neither syrinx nor Chiari, it was $35^{\circ}$.

Spinal canal diameters ranged from 13.0 to $27.0 \mathrm{~mm}$ at $\mathrm{C} 1$ and from 9.6 to $18.3 \mathrm{~mm}$ at C7. Diameters at $\mathrm{C} 1$ averaged 17.0 and $19.0 \mathrm{~mm}$ for the 2 groups of patients with Chiari and 14.6 or $14.7 \mathrm{~mm}$ in the 2 groups without Chiari. Diameters at C7 averaged 12.6 and $13.5 \mathrm{~mm}$ for the patients with Chiari and 12.2 or $12.3 \mathrm{~mm}$ for the patients without Chiari (Fig 3).

Taper ratios for $\mathrm{C} 1-\mathrm{C} 7$ ranged from -0.1 to $-2.3 \mathrm{~mm} /$ level. Taper ratios for the 4 groups differed significantly (Kruskal Willis, $P=.036$ ). For the patients with a Chiari malformation, with or without a syrinx, the taper ratio averaged 
Anteroposterior spinal canal

diameters by level

in four patient groups

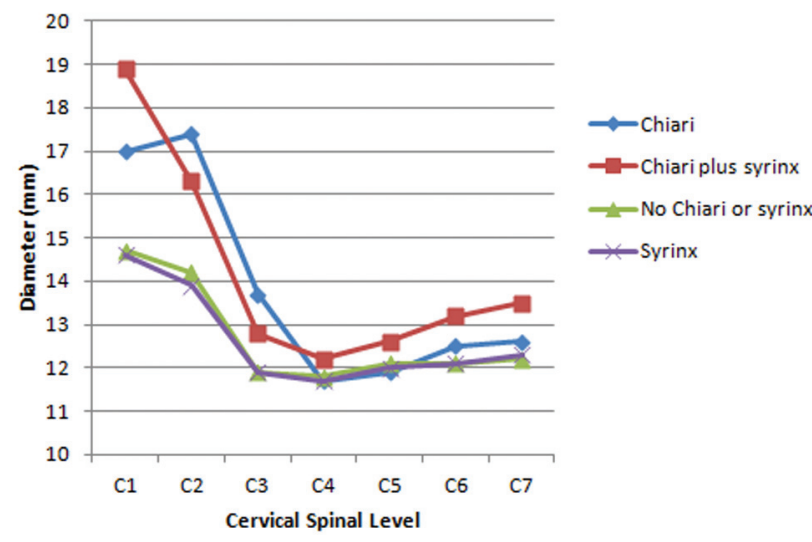

Fig 3. Average anteroposterior diameters of the cervical spinal canal plotted by cervical level in 4 groups of patients. The plots of the patients with Chiari and without syrinx appear similar as do the plots for the groups without Chiari malformation. The group with Chiari lacking a syrinx includes only 2 individuals, explaining perhaps the more erratic course of the plot. The other groups had $\geq 8$ members.

\section{Taper ratios for $\mathrm{C} 1$ to $\mathrm{C} 7$ and $\mathrm{C} 1$ to $\mathrm{C} 4$ in four patient groups}

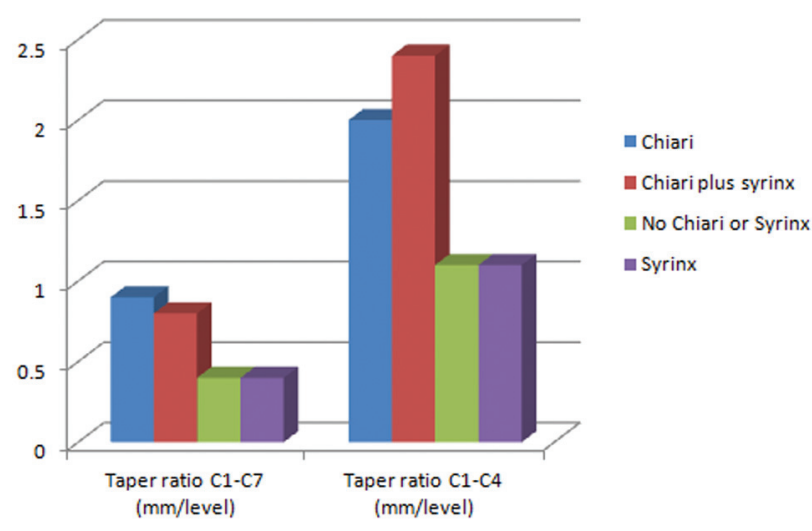

Fig 4. Taper ratios for the 4 groups of patients for $\mathrm{C} 1-\mathrm{C} 7$ and for $\mathrm{C} 1-\mathrm{C} 4$. The patients with a Chiari malformation had significantly steeper taper ratios than those without it, for both taper ratio calculations. For convenience, the negative sign is omitted from the graph.

$-0.8 \mathrm{~mm} /$ level (Fig 4). The presence of a syrinx did not substantially affect the taper ratio in patients with Chiari-that is, patients with Chiari with a syrinx had nearly the same average taper ratio as those without a syrinx. For the patients without a Chiari malformation, with or without a syrinx, the taper ratio averaged $-0.4 \mathrm{~mm} / \mathrm{level}$, and the patients without Chiari with a syrinx had the same average taper ratio as those without a syrinx (Fig 4).

Taper ratios in the 22 patients with a Chiari malformation differed significantly from those in the 32 patients without a Chiari malformation $(P=.004)$. Comparing the 2 subgroups with syrinxes, we found that the difference between those with and without Chiari was significant at $P=.033$. Because of the small number in the groups and the limited statistical power,

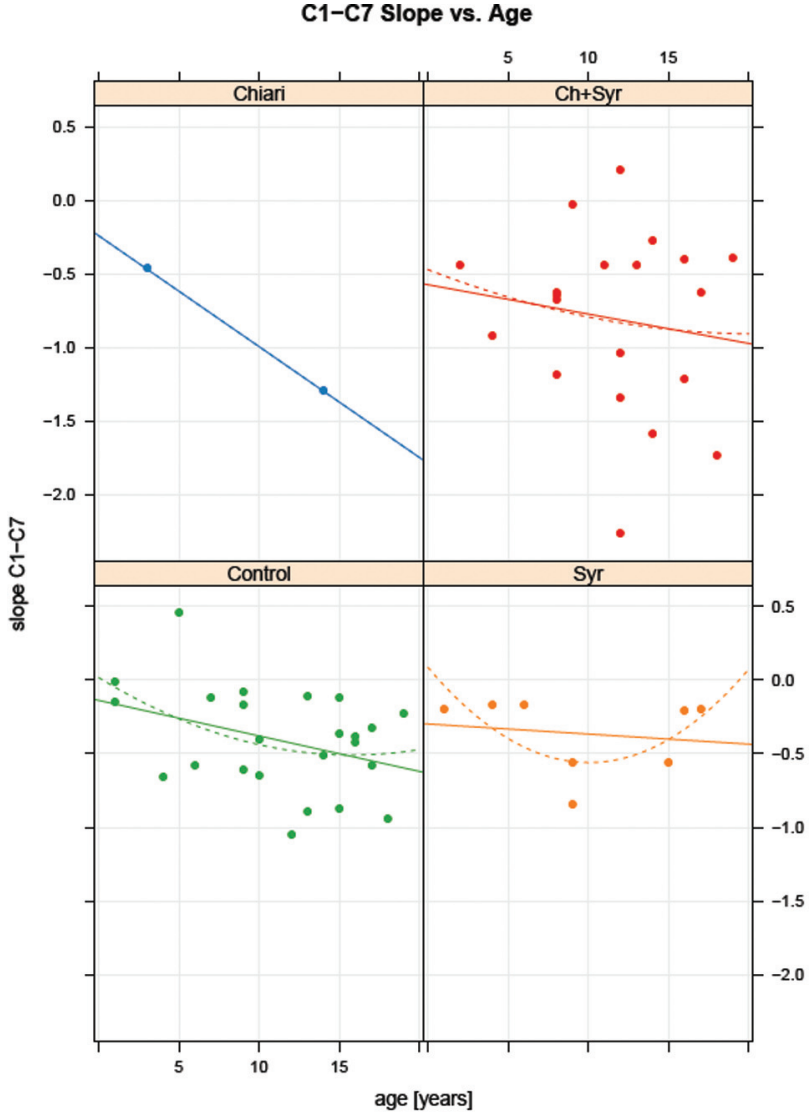

Fig 5. Taper ratio plotted by age in the 4 patient groups. A trend line is fit by linear (solid line) and by exponential (dotted line) least-squares regression. Difference between ages appears small.

taper ratio differences in subgroups with and without a syrinx were not tested for significance.

Taper ratios for C1-C4 were -2.2 and $-1.1 \mathrm{~mm} /$ level, respectively, for the patients with and without a Chiari malformation (Fig 3). The difference was significant $(P=$ $.0003)$. Scatterplots showed similar effects of age on the taper ratio in the patients with and without a Chiari malformation (Fig 5).

In the inter-reader agreement study, bias between any pair of readers was $<0.08 \mathrm{~mm}$, and limits of agreement were $<0.2$ $\mathrm{mm} /$ spinal level.

\section{Discussion}

Patients with scoliosis with a Chiari malformation have more steeply tapering upper cervical spinal canals than patients with scoliosis without a Chiari malformation. The presence of a syrinx in either group did not substantially affect the taper ratio measurement. Taper ratios are steeper from $\mathrm{C} 1$ to $\mathrm{C} 4$ than from $\mathrm{C} 1$ to $\mathrm{C} 7$. Both differ significantly between groups. The differences between the patients with and without a Chiari malformation suggest that the patients with Chiari have abnormal cervical spinal development. The steeper tapering in the patients with Chiari suggests greater acceleration of CSF velocities in the cervical spine in these patients.

These results concur with those in an another study. ${ }^{1}$ In that study, the cervical spine taper ratio from $\mathrm{C} 1$ to $\mathrm{C} 7$ was $-0.6 \mathrm{~mm} /$ level for patients with Chiari and $-0.3 \mathrm{~mm} / \mathrm{level}$ for 
controls, respectively. In that study, a syrinx did not appear to correlate with steeper taper ratios. However, age was a greater factor in that study, so the taper ratios in the 2 studies cannot be compared directly. The taper ratios in the patients with scoliosis without a Chiari malformation agree with taper ratios of -0.3 to $-0.4 \mathrm{~mm} /$ level measured in healthy adults. ${ }^{5}$ Our calculated $\mathrm{C} 1-\mathrm{C} 4$ taper ratios in a control population also agree with the $-1.1 \mathrm{~mm} /$ level reported previously. ${ }^{5}$ The techniques of measuring taper ratio and the subject ages in that study differed from ours.

This study has limitations and potential biases. The effect of enrolling only patients with MR imaging cannot be calculated. Generalization of results to the population of patients with scoliosis in general cannot be done on the basis of 1 sample of patients. Taper ratio is only an approximate 1-number representation of spinal canal diameters, especially when the tapering is nonlinear. Age, known to correlate with the taper ratio, was not controlled in our study, but the age range in our study subjects was fairly narrow. Ages and the effect of age on taper ratio appeared similar between groups in scatterplots in this study. A reader bias in the measurement of the spinal canal diameters cannot be excluded because readers could observe the position of the tonsils. From our agreement study, we estimate that reader bias is unlikely to have a significant effect on the calculations of taper ratio. Finally, our group of patients is a small one, limiting the statistical power of the study. For larger groups of patients, some correlation of taper ratio with syrinx might be found.

\section{Conclusions}

Patients with scoliosis with a Chiari I malformation have more severely tapered cervical spinal canals than patients with scoliosis without a Chiari I. This finding suggests that patients with Chiari may have abnormal development of the cervical spinal canal as well as of the posterior fossa. The finding also suggests greater acceleration of CSF in the upper cervical spinal canal in patients with Chiari than in those without it.

Disclosures: Alejandro Munoz del Rio-UNRELATED: Consultancy. I am a statistical consultant for Stratatech LLC, and I am paid by Lippincott, Williams \& Wilkins for statistical reviews of articles submitted to the Annals of Surgery.

\section{References}

1. Hirano M, Haughton V, Munoz del Rio A. Tapering of the cervical spinal canal in patients with Chiari I malformations. AJNR Am J Neuroradiol 2012;33: $1326-30$

2. Nakahara D, Yonezawa I, Kobanawa K, et al. Magnetic resonance imaging evaluation of patients with idiopathic scoliosis: a prospective study of four hundred seventy-two outpatients. Spine (Phila Pa 1976) 2011;36:E482-85

3. Inoue M, Minami S, Nakata $Y$, et al. Preoperative MRI analysis of patients with idiopathic scoliosis: a prospective study. Spine (Phila Pa 1976) 2005;30:108-14

4. Bland JM, Altman DG. Statistical methods for assessing agreement between two methods of clinical measurement. Lancet 1986;327:307-10

5. Tatarek N. Variation in the human cervical neural canal. Spine J 2005;5:623-31 